\title{
Life satisfaction and health-related quality of life - the same or a different construct? A survey in psoriasis patients
}

\section{BACKGROUND}

Numerous literature data evaluating quality of life in dermatological patients demonstrate this parameter to be considerably decreased. Psoriasis is among most studied dermatological disorders, demonstrating decreased quality of life in all examined dimensions. However, there are inconsistent data on disease influence, health-related quality of life (HRQoL) and life satisfaction in psoriatic patients. The aims of the study were the following: a) to determine the level of general life satisfaction and HRQoL in psoriasis patients; b) to differentiate factors combined with life satisfaction and HRQoL assessment and determine whether the same variables are connected with life satisfaction and HRQoL. The general life satisfaction and HRQoL are response variables. Age and sex of the patients, educational status, disease severity, expressed as Psoriasis Area and Severity Index (PASI), marital status, pruritus severity, disease duration, and family history of psoriasis (explanatory variables) were taken into consideration too.

\section{PARTICIPANTS AND PROCEDURE}

The study comprised 97 psoriasis inpatients. The Life Satisfaction Questionnaire (FLZ) and Dermatology Life Quality Index (DLQI) were used.
RESULTS

Psoriatic patients demonstrated decreased life satisfaction and HRQoL in all domains. Psoriasis patients who had partners evaluated life satisfaction in Health, Financial situation, Myself, Accommodation and Sex domains as much better than singles. Total life satisfaction and HRQoL decreased with age. The study has shown that life satisfaction is different from HRQoL.

\section{CONCLUSIONS}

The observation that total life satisfaction is not strongly determined only by medical/somatic factors could be regarded as a valuable insight for further research to determine why the majority of dermatological patients are not fully compliant.

\section{KEY WORDS}

psoriasis; psychodermatology; life satisfaction; health-related quality of life

ORganization - 1: Institute of Psychology, University of Lodz, Lodz, Poland · 2: Department of Psychodermatology,

Medical University of Lodz, Lodz, Poland

AUthors' CONTRiButions - A: Study design - B: Data collection - C: Statistical analysis - D: Data interpretation .

E: Manuscript preparation · F: Literature search · G: Funds collection

CORResponding AUthor - Joanna Miniszewska, Ph.D., Institute of Psychology, University of Lodz, 10/12 Smugowa Str., 91-433 Lodz, Poland, e-mail: jminisz@poczta.onet.pl 


\section{BACKGROUND}

Numerous literature data evaluating quality of life in dermatological patients demonstrate this parameter to be considerably decreased. Psoriasis is among the most studied dermatological disorders, demonstrating decreased quality of life in all examined dimensions (Krueger et al., 2001; de Korte, Mombers, Bos, \& Sprangers, 2004; Innamorati et al., 2016; Petraškienè, Valiukevičienè, \& Macijauskienè, 2016; Sarkar, Chugh, \& Bansal, 2016; Raddadi et al., 2016; Rahman, Shahbaz, Nadeem, \& Kazmi, 2018).

The majority of data concentrate on health-related quality of life (HRQoL). The traditional conceptualization of the above entity, originating in the pathogenetic model of health and the health system, focuses on assessment of the influence of physical status on a human being, both functioning (physical, psychological and social) and restrictions in this functioning (Laudet, Becker, \& White, 2009).

Szabo (1996) points out that many methods evaluating HRQoL in fact examine only the subjective perception of the influence of the disease and not quality of life per se. In the last decade, when the reconceptualization of the definition of health (according to the WHO) took place, a holistic approach to health was postulated. So now, health is defined not only as a lack of any disease, but as a state of physical, psychological and social well-being. Thus, general life satisfaction and satisfaction in numerous roles in one's life are desired and should be promoted. The interest of experts shifted from restrictions in one's functioning towards general well-being.

It is more and more often underlined that concentration only on the physical consequences of the disease is not sufficient. A wider perspective allowing one to evaluate psychosocial functioning of the patients suffering from somatic disease is much more desired (Bonomi, Patrick, Bushnell, \& Martin, 2000; Skevington, Lotfy, \& O’Connell, 2004). Namely, a psoriasis patient may state that psoriasis greatly influences one's social contacts, but at the same time, the patient can evaluate one's social life as vastly satisfactory. So, on the one hand problems arising from functioning in society could have too narrow an approach, whereas on the other hand importance of the disease itself could be omitted.

Thus, the following question arises: what exactly do we want to know by using quality of life? Are we interested in functional aspects of a human being influenced by psoriasis or rather one's general functioning in society? Maybe it is worth combining both the above approaches to the problem and to assess functioning of the dermatological patients from both perspectives?

Taking into account the above arguments, the current work concentrates on both wider perspective of life satisfaction and HRQoL. Life satisfaction differs from quality of life by presenting more stable and objective character, lower susceptibility to time changes and external and internal influence (Campbell, 1981). HRQoL is defined as the functional effect of the disease and its treatment experienced by the patient (Shipper, 1990).

The aims of the study were the following: a) to determine the level of the general life satisfaction and HRQoL in psoriasis patients; b) to differentiate factors combined with life satisfaction and HRQoL assessment and determine whether the same variables are connected with life satisfaction and HRQoL.

The general life satisfaction and HRQoL are response variables. Age and sex of the patients, educational status, disease severity, expressed as Psoriasis Area and Severity Index (PASI), marital status, pruritus severity, disease duration, and family history of psoriasis (explanatory variables) were taken into consideration too.

The following hypotheses were elaborated:

1. Psoriatic patients demonstrate decreased life satisfaction in all the examined aspects and decreased HRQoL in comparison to the general population.

2. Life satisfaction and HRQoL are connected with different variables (both medical and socio-demographic).

\section{PARTICIPANTS AND PROCEDURE}

\section{PARTICIPANTS}

The study comprised 115 patients who were hospitalized at the dermatology departments at the time of evaluation (from February to December 2017). The study included people diagnosed with psoriasis vulgaris (based on medical interview), without other serious chronic diseases (somatic and psychological). After rejecting surveys of people who do not meet the criteria 97 psoriatic patients remained (43 females and 54 males). The study was approved by the Medical University of Lodz Bioethics Committee and the patients gave their informed consent to participate in the study. Detailed characteristics of the patients are presented in Table 1.

\section{MEASURES}

Life Satisfaction Questionnaire (FLZ). FLZ by Fahrenberg, Myrtek, Schumacher, and Brähler (2000), is a self-administered questionnaire composed of 10 subscales: 1 . Health - high results indicate high satisfaction with one's general health, psychological and physical status, high resistance to pain and diseases $(M \pm S D$ for normalization group $34.61 \pm 7.09)$; 2. Job and work - high results indicate high satisfaction with one's job and work place $(M \pm S D$ for 
Table 1

Characteristics of participants $(N=97)$

\begin{tabular}{|c|c|c|c|}
\hline & $\begin{array}{c}\text { Women } \\
n=43\end{array}$ & $\begin{array}{c}\text { Men } \\
n=54\end{array}$ & $\begin{array}{c}\text { Total } \\
N=97\end{array}$ \\
\hline \multicolumn{4}{|l|}{ Education, $n(\%)$} \\
\hline Primary & $8(18.60)$ & $13(24.07)$ & $21(21.64)$ \\
\hline Professional & $30(69.77)$ & $36(66.66)$ & $66(68.05)$ \\
\hline Secondary & $5(11.63)$ & $4(7.40)$ & $9(9.27)$ \\
\hline Higher & - & $1(1.85)$ & $1(1.03)$ \\
\hline \multicolumn{4}{|l|}{ Civil status, $n(\%)$} \\
\hline Couples & $40(93.03)$ & $37(68.52)$ & $77(79.38)$ \\
\hline Singles & $3(6.97)$ & $17(31.48)$ & $20(20.62)$ \\
\hline \multicolumn{4}{|l|}{ Psoriasis family history, $n(\%)$} \\
\hline Positive & $17(39.53)$ & $27(50.00)$ & $44(45.36)$ \\
\hline Negative & $26(60.47)$ & $27(50.00)$ & $53(54.64)$ \\
\hline \multicolumn{4}{|l|}{ Pruritus, $n(\%)$} \\
\hline Present & $41(95.34)$ & $45(83.33)$ & $86(88.65)$ \\
\hline Absent & $3(4.66)$ & $9(16.67)$ & $11(11.35)$ \\
\hline Mean pruritus $(S D)$ & $4.60(2.35)$ & $4.29(2.61)$ & $4.30(2.60)$ \\
\hline Mean PASI $(S D)$ & $10.45(6.32)$ & $15.81(7.67)$ & $13.43(7.65)$ \\
\hline Mean disease duration $(S D)$ years & $14.43(7.96)$ & $20.93(11.39)$ & $16.58(10.64)$ \\
\hline Mean age $(S D)$ & $40.12(11.61)$ & $43.65(13.15)$ & $41.64(12.36)$ \\
\hline
\end{tabular}

Note. PASI - Psoriasis Area and Severity Index.

normalization group $34.78 \pm 7.40$ ); 3 . Financial situation - high results indicate high satisfaction with one's life and income $(M \pm S D$ for normalization group $31.20 \pm 7.94)$; 4. Leisure time - high results indicate one's satisfaction with length of holidays and leisure time, time allocated for family, relatives and hobby activities $(M \pm S D$ for normalization group $34.18 \pm 7.57$ ); 5. Marriage/partnership - general satisfaction from one's partner, his/her needs, common activities, frankness, understanding, help, feelings of safety $(M \pm S D$ for normalization group $38.65 \pm 8.09)$; 6 . Children - high results indicate positive relationships with one's children $(M \pm S D$ for normalization group $39.81 \pm 5.49$ ); 7. Myself - high results denote people satisfied with numerous aspects of oneself, i.e. life choices, talents, character, personality, up-to-date life $(M \pm S D$ for normalization group $35.54 \pm 6.14$ ); 8. Friends, acquaintance, relatives - higher results indicate good level of satisfaction with one's relations with friends, relatives and all the third parties $(M \pm S D$ for normalization group $35.91 \pm 5.44)$; 9. Accommodation - high results denote one's satisfaction with the size, state, location, connection and costs of the place where one is living
$(M \pm S D$ for normalization group $36.00 \pm 6.23) ; 10$. Sex - high results mean positive assessment of one's sexual activities, contacts and relationships in this field ( $M \pm S D$ for normalization group $35.34 \pm 30.33$ ). Total life satisfaction index is calculated by adding up subsequent crude results of 7 subscales $(M \pm S D$ for normalization group $242.78 \pm 30.33$ ). Three subscales, namely fob and work, Marriage/partnership, Children, are omitted because they were not filled in by a considerably high proportion of responders. The Polish version of this questionnaire is characterized by very good psychometric values including Cronbach's $\alpha$ coefficient (for the whole questionnaire .94) (Chodkiewicz, 2009). In the present study Cronbach's $\alpha$ coefficient for whole questionnaire is .96 (various subscales from .85-.97).

Dermatology Life Quality Index (DLQI). This scale was developed by Finley and Khan (1994), with the Polish adaptation by Szepietowski et al. (2004), to assess disability resulting from dermatological disease, namely HRQoL. It is a 10-question, self-administered questionnaire rating the quality of daily functioning on a four-point scale from 0 to 3 . Patients are asked to recall symptoms and feelings, daily activities, lei-
Life satisfaction and quality of life in psoriasis 
sure, work and school, personal relationships and treatment for the past week. The higher the score, the worse the HRQoL is. Scores between 0 and 1 are regarded as lack of disease influence on HRQoL, between 2 and 5 as mild influence, from 6 to 10 as medium influence, between 11 and 20 as a strong influence and above 21 as a very strong influence on HRQoL. The Polish version of DLQI presents good psychometric values with Cronbach's $\alpha$ coefficient equal to .90 (in the present study it is .85).

Psoriasis Area and Severity Index (PASI). PASI is a gold standard of psoriasis severity evaluation (Fredriksson \& Pettersson, 1978). Erythema, infiltration and desquamation are evaluated separately for each region of the human body, i.e. head and neck, chest, upper and lower limbs on a scale 0 to 4 . Area of involvement is also calculated for each region on a scale 0 to 6 . Total score is calculated based on different coefficients and adding up the single scores for each region. The score ranges from 0 to 72 , and the higher the score the more severe psoriasis is. A score above 10 is generally regarded as severe involvement.

Visual Analog Scale (VAS). A horizontal VAS was used to evaluate patients with regards to subjective measure of pruritus, with the anchors of no pruritus at 0 and most severe at 10 . The patients were asked to assess their pruritus in the last 4 weeks (Reich et al., 2012).

\section{STATISTICAL ANALYSIS}

Statistical analyses were performed using the IBM SPSS Statistics for Windows (version 20.0). Results are reported as mean \pm standard deviation $(M \pm S D)$. The Shapiro-Wilk test was used to verify the distribution of results. The distribution of data was checked and did not differ significantly from a normal distribution. Student's $t$-test $(t)$ was employed to determine statistically significant differences between the obtained results. Pearson's correlation coefficient was used to evaluate the correlation between the examined variables (which are linear). Statistical significance was set at $p<.05$.

Isolated data gaps were random, as evidenced by the negligible Little test $\left(\chi^{2}=501.50, d f=515, p=.657\right)$. Thus, in accordance with contemporary recommendations we replaced them by using the EM algorithm (Graham, 2009). Further analyses are already carried out on the basis of the data supplemented.

\section{RESULTS}

The first part of the performed analysis was evaluation of life satisfaction level and HRQoL in the whole group of psoriatic patients and separately for females and males. Detailed results are presented in Table 2.

Table 2

Results of life satisfaction and HRQoL in the examined group of patients according to sex

\begin{tabular}{|c|c|c|c|c|c|c|c|c|c|c|}
\hline & \multicolumn{2}{|c|}{$\begin{array}{l}\text { Total } \\
n=97\end{array}$} & \multicolumn{2}{|c|}{$\begin{array}{c}\text { Women } \\
n=43\end{array}$} & \multicolumn{2}{|c|}{$\begin{array}{l}\text { Men } \\
N=54\end{array}$} & \multirow[t]{2}{*}{$d$} & \multirow[t]{2}{*}{$d f$} & \multirow[t]{2}{*}{$t$} & \multirow[t]{2}{*}{$p$} \\
\hline & $M$ & $S D$ & $M$ & $S D$ & $M$ & $S D$ & & & & \\
\hline \multicolumn{11}{|l|}{ Life satisfaction } \\
\hline Health & 26.06 & 8.01 & 26.06 & 8.20 & 25.62 & 7.91 & 0.05 & 95 & 0.59 & .555 \\
\hline Job and work & 29.71 & 12.23 & 29.71 & 7.36 & 30.05 & 8.96 & 0.04 & 95 & -0.30 & .756 \\
\hline Financial situation & 26.38 & 8.62 & 26.38 & 9.05 & 25.40 & 8.21 & 0.11 & 95 & 1.25 & .215 \\
\hline Leisure time & 31.57 & 6.44 & 31.57 & 6.10 & 30.57 & 6.58 & 0.15 & 95 & 1.73 & .080 \\
\hline Children & 38.44 & 5.44 & 38.44 & 6.03 & 39.00 & 6.01 & 0.09 & 95 & 0.42 & .504 \\
\hline Myself & 33.14 & 6.77 & 33.14 & 7.10 & 32.29 & 6.44 & 0.12 & 95 & 1.38 & .167 \\
\hline $\begin{array}{l}\text { Friends, acquaintance, } \\
\text { relatives }\end{array}$ & 33.42 & 6.54 & 33.42 & 6.38 & 31.88 & 6.32 & 0.24 & 95 & 2.66 & .013 \\
\hline Accommodation & 33.17 & 6.99 & 33.17 & 6.50 & 32.79 & 7.39 & 0.05 & 95 & 0.59 & .555 \\
\hline Marriage/partnership & 31.57 & 12.55 & 31.57 & 11.99 & 29.98 & 13.47 & 0.12 & 95 & 1.40 & .162 \\
\hline Sex & 32.21 & 8.69 & 32.21 & 8.95 & 33.35 & 8.38 & 0.13 & 95 & -1.44 & .153 \\
\hline Total life satisfaction & 215.97 & 36.86 & 215.97 & 34.73 & 211.94 & 38.31 & 0.11 & 95 & 1.21 & .225 \\
\hline HRQoL & 14.47 & 7.31 & 14.47 & 7.50 & 15.41 & 7.09 & 0.12 & 95 & -1.50 & .135 \\
\hline
\end{tabular}

Note. HRQoL - health-related quality of life. 
The obtained results for life satisfaction were compared with the standardization group (Chodkiewicz, 2009). The examined group of patients demonstrated significantly decreased life satisfaction in all the studied dimensions. Psoriasis patients assessed their Health and Financial situation as the worse ones. Mean DLQI results also indicated a significantly decreased HRQoL in this group of patients (Finlay $\&$ Khan, 1994). The only difference in life satisfaction between females and males was noted in the Friends, acquaintance, relatives domain. Females were significantly more satisfied with the above relationships than males.

Life satisfaction and HRQoL were also analyzed in relation to educational level, civil status, and family history of psoriasis, but this analysis did not reveal any significant differences $(p>.05)$.

Further analysis demonstrated that psoriasis patients who had partners evaluated their life satisfaction as much higher in the following dimensions: Health, Financial situation, Myself, Accommodation and Sex, than singles. The results are reported in Table 3.

However, being in stable relationships was not a differentiating factor as regards HRQoL $(p>.05)$ (data not presented).

The final step of the analysis was focused on the relationship between life satisfaction and HRQoL as regards patients' age, disease duration, severity of psoriasis and pruritus intensity. Detailed data are presented in Table 4.
Total life satisfaction decreases with age, but other studied variables are not related to this parameter. With age, life satisfaction in the following domains Health, Financial situation, Leisure time, Friends, acquaintance, relatives and Sex - also significantly decreases. Psoriasis severity adversely correlates with Marriage/partnership domain in life satisfaction, i.e. the more severe the lesions, the less satisfied are the patients in this domain $(r=-.25, p<.05)$. Moreover, the more severe the pruritus, the lower the life satisfaction in the Sex domain $(r=-.24, p<.05)$. As regards HRQoL, only severity of the disease expressed as PASI score correlates positively with this parameter $(r=.21, p<.05)$, i.e. the more severe the disease, the worse HRQoL is.

\section{DISCUSSION}

Our results demonstrated significantly worse life satisfaction in the examined group of psoriasis patients than in the normalization group. Only life satisfaction in the Children subscale was comparable to the one obtained in the normalization group. The lowest life satisfaction was noted in Health and Financial situation subscales. HRQoL, measured by DLQI, was also significantly lower in the examined group of psoriasis patients. The obtained results are in agreement with most of the literature data (e.g. Ljosaa, Mork, Stubhaug, Moum, \& Wahl, 2012; Uttjek, Dufaker,
Life satisfaction and quality of life in psoriasis

Table 3

Life satisfaction and HRQoL in relation to marriage/partnership

\begin{tabular}{|c|c|c|c|c|c|c|c|c|}
\hline & \multicolumn{2}{|c|}{$\begin{array}{l}\text { Singles } \\
(n=20)\end{array}$} & \multicolumn{2}{|c|}{$\begin{array}{c}\text { Couples } \\
(n=77)\end{array}$} & \multirow[t]{2}{*}{$d$} & \multirow[t]{2}{*}{$d f$} & \multirow[t]{2}{*}{$t$} & \multirow[t]{2}{*}{$p$} \\
\hline & $M$ & $S D$ & $M$ & $S D$ & & & & \\
\hline \multicolumn{9}{|l|}{ Life satisfaction } \\
\hline Health & 22.85 & 7.40 & 27.14 & 7.75 & 0.56 & 95 & -2.22 & .020 \\
\hline Job and work & 30.85 & 22.24 & 29.50 & 8.06 & 0.08 & 95 & 0.43 & .664 \\
\hline Financial situation & 22.15 & 7.39 & 27.48 & 8.67 & 0.66 & 95 & -2.51 & .013 \\
\hline Leisure time & 30.70 & 5.18 & 31.75 & 6.77 & 0.17 & 95 & -0.64 & .522 \\
\hline Children & 19.95 & 18.60 & 27.53 & 17.60 & 0.41 & 95 & -1.69 & .095 \\
\hline Myself & 28.50 & 5.38 & 34.40 & 6.25 & 1.01 & 95 & -3.20 & .001 \\
\hline Friends, acquaintance, relatives & 32.40 & 5.49 & 33.84 & 6.71 & 0.23 & 95 & -0.88 & .375 \\
\hline Accommodation & 30.40 & 9.08 & 33.85 & 6.26 & 0.44 & 95 & -2.03 & .044 \\
\hline Sex & 24.65 & 6.22 & 34.48 & 7.77 & 0.39 & 95 & -5.22 & $<.001$ \\
\hline Total life satisfaction & 192.65 & 29.98 & 223.05 & 35.33 & 0.92 & 95 & -3.52 & .001 \\
\hline HRQoL & 13.69 & 8.22 & 14.78 & 6.96 & 0.14 & 95 & -0.67 & .495 \\
\hline
\end{tabular}

Note. HRQoL - health-related quality of life. 
Table 4

Correlation coefficients between life satisfaction, HRQoL and patients' age, disease duration, severity of psoriasis and pruritus intensity

\begin{tabular}{lcccc}
\hline & Patients' age & Psoriasis duration & PASI & Pruritus \\
\hline Life satisfaction & & & & -.17 \\
Health & $-.24^{*}$ & -.04 & -.06 & .02 \\
Job and work & .20 & .04 & -.05 & -.17 \\
Financial situation & $-.30^{* *}$ & -.04 & .12 & -.05 \\
Leisure time & $-.23^{*}$ & -.03 & -.02 & -.11 \\
Children & .15 & .08 & -.06 & -.15 \\
Myself & -.16 & -.04 & -.11 & -.08 \\
Friends, acquaintance, relatives & $-.25^{*}$ & -.03 & .06 & .03 \\
Accommodation & -.01 & -.01 & $-.25^{*}$ & -.09 \\
Marriage/partnership & .02 & -.03 & -.12 & $-.24^{*}$ \\
Sex & $-.28^{* *}$ & -.16 & -.10 & -.14 \\
Total life satisfaction & $-.30^{* *}$ & -.05 & $.21^{*}$ & .10 \\
HRQoL & .15 & -.03 & & \\
\hline
\end{tabular}

Note. HRQoL - health-related quality of life; PASI - Psoriasis Area and Severity Index; ${ }^{*} p<.05 ;{ }^{* *} p<.01$.

Nygren, \& Stenberg, 2004). Only one report (Reimus, Vingerhoets, Soons, \& Korstanje, 2007) shows that psoriatics' life satisfaction did not differ significantly from the normal group (while psoriasis patients scored significantly lower on subjective health status and psychologic well-being). It should be emphasized that we examined only inpatients, so most of them have very severe or difficult to treat skin disorders.

When analyzing life satisfaction and HRQoL in relation to sex, only the Friends, acquaintance, relatives subscale was a differentiating factor. Of note, women were more satisfied with social contacts than men. It should be noted that men had more lesions and longer duration of the disease. The obtained results concerning HRQoL are in accordance with those of Fortune, Main, O'Sullivan, and Griffiths (1997), who observed that men and women suffering from psoriasis did not differ as regards this parameter's evaluation. The above results were further confirmed by de Korte et al. (2004). However, it is worth pointing out that other researchers did not observe similar results. On the contrary, they demonstrated that psoriasis causes significantly worse HRQoL in women in comparison to men (Dalgard, Svensson, Holm, \& Sundby, 2004; Papadopoulos \& Walker, 2003; Uttjek et al., 2004). To the best of our knowledge, there are no data on the sex differences as regards life satisfaction in psoriasis patients.

We also demonstrated that psoriasis patients who have a spouse or partner are more satisfied with life in numerous dimensions (Health, Financial situation, Myself, Accommodation and Sex). Such an ob- servation brings to mind the extremely important role of social support (Haduch et al., 2008; Sacco, 2006). Significant differences in life satisfaction between patients with partners and without partners suggest that a stable relationship could be regarded as a specific highly protective buffer from stressors originating in the disease itself. Literature data indicate the very important fact that even a single close relationship is sufficient to serve as a very good buffer when confronted with stressful situations (Cohen \& Wills, 1985). Such support plays a functional role and could be regarded as instrumental support (direct help), informative support (advice) or simply as a form of high respect for the person in question, which is highly valuable for every human being. It is very interesting that being in a stable relationship does not differentiate the examined psoriasis patients as regards HRQoL. The latter observation seems to be in agreement with the observation of Szabo (1996), who pointed out that tools used for HRQoL evaluation examine mainly symptoms of the disease.

Our results demonstrated that such variables as educational level, civil status and family history of psoriasis did not differentiate patients as regards both their life satisfaction and HRQoL, which is in agreement with Diener and Lucas (1999), who pointed out that socio-demographic variables are generally responsible for a minute variance in life satisfaction.

The final step of our analysis examined correlations between life satisfaction, HRQoL and patients' age, disease duration, severity of psoriasis and pruritus. 
Total life satisfaction and the following domains adversely correlated with the patients' age: Health, Financial situation, Leisure time, Friends, acquaintance, relatives and Sex. There are also relationships between age and satisfaction with life in healthy individuals although the direction of some dependence is reversed - for example, age has a positive relationship with satisfaction with finances (25). On the other hand, in the present study, HRQOL does not correlate with age but only with the severity of the disease.

Other authors' results concerning patients' age and quality of life are inconsistent (de Korte et al., 2004; Diener \& Lucas, 1999). Steuden and Janowski (2001) demonstrated that psoriasis much more strongly decreases quality of life of older patients than younger ones, whereas McKenna and Stern (1997) and Zachariae et al. (2004) noted the opposite results. Psoriasis severity adversely correlated only with life satisfaction in the Marriage/partnership subscale. Moreover, more severe pruritus correlated with lower life satisfaction with Sex. So, medical variables, such as disease severity and its duration, together with pruritus intensity, seem not be related to total life satisfaction. On the other hand, HRQoL correlated only with the disease severity. The above observation seems to confirm the hypothesis that many tools developed to assess HRQoL in fact can evaluate only the subjective perception of the influence of the disease on the patient (Szabo, 1996).

Literature data on the correlation between quality of life, life satisfaction and disease severity in psoriasis are inconsistent (de Korte et al., 2004; Reimus et al., 2007). However, any definite conclusions are very difficult to draw because very different tools are used by different research groups to assess quality of life. It is of interest that our results did not demonstrate any correlation between pruritus intensity and quality of life assessed by DLQI. Literature data support such a correlation (de Korte et al., 2004).

The obtained results suggest that due to the complexity of the problem, there is an urgent need to search for different, than medical, parameters which could influence life satisfaction in psoriasis patients. Maybe personality traits should be taken into account, especially as McCrae and Costa (1991) suggested that extroversion and neuroticism can form the stable basis for evaluation of one's life satisfaction. In other words, for an extravert person the same world will appear much better than for a neurotic one. Life satisfaction in healthy persons and those suffering from diseases other than psoriasis correlates with different personality aspects such as optimism or personality type D (Argyle, 1987; Basińska \& Drozdowska, 2012; Basińska \& Kasprzak, 2012; Basińska \& Woźniewicz, 2012; Paika et al., 2010; Røysamb \& Strype, 2002; Saeed, Niazi, \& Almas, 2011; Zalewska, Miniszewska, Chodkiewicz, \& Narbutt, 2007).
As for study limitations, we studied only inpatients, so it is not possible to extrapolate the results to all people with psoriasis. What is more, our patient group was comparatively small. The size of the group did not allow us to perform further division into females and males with and without partners. Such comparison could reveal interesting and useful results. The lack of a comparison group is a further limitation of this survey. Moreover, a general questionnaire evaluating HRQoL was not employed. Further research should check whether e.g. the SF-36 questionnaire together with life satisfaction could also reveal such considerable differences as in our current study. Our study took into account only selected socio-demographic and medical variables. It did not take into consideration such parameters as anxiety and depression, which could further add some advantage to the obtained results. However, the obtained results have high potential for conducting further studies in a psoriasis group of all patients (which are under various treatment regimens).

In conclusion, the obtained results demonstrate that life satisfaction is totally different from HRQoL. Life satisfaction is a much broader entity and determined by different variables than HRQoL. So, our results that global life satisfaction is not strongly determined by medical/somatic factors could be regarded as a direction towards determining why the majority of patients are not fully compliant. Maybe global problems of compliance are determined by patients' difficulties in satisfying their important needs in life. Thus, the latter could be in opposition to treatment regimens and following those regimens could mean total dissatisfaction of the most important needs for the patients. So, not surprisingly, such a situation could result in noncompliance of the patients. Thus, it seems necessary to identify dysfunctional areas in the groups of psoriasis patients before introduction of any support to those patients. However, older and single patients should be taken under special care.

\section{ACKNOWLEDGEMENTS}

This work was supported by the research grant no. NN 404-029-438 and statutory Medical University of Lodz research grant no. 503/1-137-04/503-01.

\section{References}

Argyle, M. (1987). Psychology of happiness. London: Routledge.

Basińska, M. A., \& Drozdowska, M. (2012). Type A behavior in individuals with psoriasis as a determinant of acceptance of the illness. Advances in Dermatology and Allergology/Postępy Dermatologii
Life satisfaction and quality of life in psoriasis 
i Alergologii, 29, 432-439. https://doi.org/10.5114/ pdia.2012.32390

Basińska, M., \& Kasprzak, A. (2012). The relationship between strategies of coping with stress and acceptance of illness among patients with psoriasis. Dermatology Review/Przegląd Dermatologiczny, 99, 692-700.

Basińska, M., \& Woźniewicz, A. (2012). Emotional intelligence in psoriasis patients as a determinant of acceptance of illness. Dermatology Review/Przegląd Dermatologiczny, 99, 202-209.

Joanna Miniszewska, Jan Chodkiewicz, Alicja OgraczykPiotrowska, Anna ZalewskaJanowska

Bonomi, A. E., Patrick, D. L., Bushnell, D. M., \& Martin, M. (2000). Validation of the United States' version of the World Health Organization Quality of Life (WHOQOL) instrument. Journal of Clinical Epidemiology, 53, 1-12. https://doi.org/10.1016/ S0895-4356(99)00123-7

Campbell, A. (1981). The sense of well-being in America: Recent patterns and trends. New York: McGraw-Hill.

Chodkiewicz, J. (2009). Adaptacja polska Kwestionariusza Zadowolenia z Życia (FLZ) [Polish adaptation of the Life Satisfaction Questionnaire (FLZ)]. Studia Psychologiczne, 47, 5-21.

Cohen, S., \& Wills, T. A. (1985). Stress, social support, and the buffering hypothesis. Psychological Bulletin, 98, 310-357. https://doi.org/10.1037/00332909.98.2.310

Dalgard, F., Svensson, A., Holm, J., \& Sundby, J. (2004). Self-reported skin morbidity among adults: associations with quality of life and general health in a Norwegian survey. Journal of Investigative Dermatology, 9, 120-125. https://doi.org/10.1046/j.10870024.2003.09111.x

de Korte, J., Mombers, F. M., Bos, J. D., \& Sprangers, M. A. (2004). Quality of life in patients with psoriasis: a systematic literature review. Journal of Investigative Dermatology, 9, 140-147. https://doi. org/10.1046/j.1087-0024.2003.09110.x

Diener, E., \& Lucas, R. E. (1999). Personality and subjective well-being. In: D. Kahneman, E. Diener, \& N. Schwarz (Eds.), Well-being: The foundations of hedonic psychology (pp. 213-229). New York: Russell Sage Foundation.

Fahrenberg, J., Myrtek, M., Schumacher, J., \& Brähler, E. (2000). Fragebogen zur Lebenszufriedenheit [The Life Satisfaction Questionnaire]. Göttingen: HogrefeVerlag für Psychologie.

Finlay, A. Y., \& Khan, G. K. (1994). Dermatology Life Quality Index (DLQI): a simple practical measure for routine clinical use. Clinical and Experimental Dermatology, 19, 210-216. https://doi.org/ 10.1111/j.1365-2230.1994.tb01167.x

Fortune, D. G., Main, C. J., O’Sullivan, T. M., Griffiths, C. E. M. (1997). Quality of life in patients with psoriasis: The contribution of clinical variables and psoriasis-specific stress. British Journal of Dermatology, 137, 755-760. https://doi.org/10.1046/ j.1365-2133.1997.19472062.x
Fredriksson, T., \& Pettersson, U. (1978). Severe psoriasis - oral therapy with a new retinoid. Dermatologica, 157, 238-244. https://doi.org/10.1159/000250839

Graham, J. W. (2009). Missing data analysis: Making it work in the real world. Annual Review of Psychology, 60, 549-576. https://doi.org/10.1146/annurev. psych.58.110405.085530

Haduch, I., Hawro, T., Miniszewska, J., Chodkiewicz, J., Sysa-Jędrzejowska, A., \& Zalewska, A. (2008). Social support and general mental health status in psoriatic patients. Clinical Dermatology, 10, 9-13.

Innamorati, M., Quinto, R. M., Imperatori, C., Lora, V., Graceffa, D., Fabbricatore, M., Lester, D., Contardi, A., \& Bonifati, C. (2016). Health-related quality of life and its association with alexithymia and difficulties in emotion regulation in patients with psoriasis. Comprehensive Psychiatry, 70, 200-208. https://doi.org/10.1016/j.comppsych.2016.08.001.

Krueger, G., Koo, J., Lebwohl, M., Menter, A., Stern, R. S., \& Rolstad, T. (2001). The impact of psoriasis on quality of life: Results of a 1998 National Psoriasis Foundation patient-membership survey. Archives of Dermatology, 137, 280-284.

Laudet, A., Becker, J. B., \& White, W. L. (2009). Don't wanna go through that madness no more: Quality of life satisfaction as predictor of sustained remission from illicit drug misuse. Substance Use \& Misuse, 44, 227-252. https://doi.org/10.1080/108260808 02714462

Ljosaa, T. M., Mork, C., Stubhaug, A., Moum, T., \& Wahl, A. K. (2012). Skin pain and skin discomfort is associated with quality of life in patients with psoriasis. Journal of the European Academy of Dermatology and Venereology, 26, 29-35. https:// doi.org/10.1111/j.1468-3083.2011.04000.x

McCrae, R. R., \& Costa, P. T. (1991). Adding liebe und arbeit: The full five-factor model and well-being. Personality and Social Psychology Bulletin, 17, 227232. https://doi.org/10.1177/014616729101700217

McKenna, K., \& Stern, R. S. (1997). The impact of psoriasis on the quality of life of patients from the 16-center PUVA follow up cohort. Journal of the American Academy of Dermatology, 36, 388-394. https://doi.org/10.1016/s0190-9622(97)80214-9

Paika, V., Almyroudi, A., Tomenson, B., Creed, F., Kampletsas, E., Siafaka,V., Gkika, S., Mavreas, V., Pavlidis, N., \& Hyphantis, T. (2010). Personality variables are associated with colorectal cancer patients' quality of life independent of psychological distress and disease severity. Psycho-Oncology, 19, 273-282. https://doi.org/10.1002/pon. 1563

Papadopoulos, L., \& Walker, C. (2003). Personality, coping and sex as psychosocial aspects of psoriatic arthropathy. Dermatology and Psychosomatics, 4, 27-32. https://doi.org/10.1159/000070532

Petraškienè, R., Valiukevičienè, S., \& Macijauskienė, J. (2016). Associations of the quality of life and psychoemotional state with sociodemographic fac- 
tors in patients with psoriasis. Medicina, 52, 238 243. https://doi.org/10.1016/j.medici.2016.07.001

Raddadi, A. A., Jfri, A., Samarghandi, S., Matury, N., Habibullah, T., Alfarshoti, M., \& Mahdi, A. (2016). Correlation between severity index (PASI) and quality of life index (DLQI) based on the type of treatment. Journal of Dermatology \& Dermatologic Surgery, 20, 15-18. https://doi.org/10.1016/j.jdds. 2015.05.002

Rahman, S., Shahbaz, A., Nadeem, M., \& Kazmi, A. H. (2018). Quality of life assessment in patients of psoriasis. Journal of Pakistan Association of Dermatologists, 28, 186-192.

Reich, A., Heisig, M., Quan Phan, N., Taneda, K., Takamori, K., Takeuchi, S., Furue, M., Blome, C., Augustin, M., Ständer, S., \& Szepietowski, J. (2012). Visual Analogue Scale: Evaluation of the instrument for the assessment of pruritus. Acta Dermato-Venereologica, 92, 497-501. https://doi.org/10.2340/00015555-1265

Reimus, J., Vingerhoets, J., Soons, P., \& Korstanje, M. (2007). Suffering in psoriasis patients: Its relation with illness severity and subjective well-being. International Journal of Dermatology, 46, 1042-1045. https://doi.org/10.1111/j.1365-4632.2007.03191.x

Røysamb, E., \& Strype, J. (2002). Optimism and pessimism: Underlying structure and dimensionality. Journal of Social and Clinical Psychology, 21, 1-19. https://doi.org/10.1521/jscp.21.1.1.22403

Sacco, W. P. (2006). Diabetes and depression: The role of social support and medical symptoms. Journal of Behavioral Medicine, 29, 523-531. https://doi.org/ 10.1007/s10865-006-9072-5

Saeed, T., Niazi, G. S., \& Almas, S. (2011). Type-D personality: a predictor of quality of life and coronary heart disease. Eastern Mediterranean Health Journal, 17, 46-50.

Sarkar, R., Chugh, S., \& Bansal, S. (2016). General measures and quality of life issues in psoriasis. Indian Dermatology Online Journal, 7, 481-488. https://doi. org/10.4103/2229-5178.193908

Shipper, H. (1990). Quality of life: Principles of the clinical paradigm. Journal of Psychosocial Oncology, 8, 171-185. https://doi.org/10.1300/J077v08n02_09

Skevington, S. M., Lotfy, M., \& O’Connell, K. (2004). The World Health Organization's WHOQOL-BREF quality of life assessment: Psychometric properties and results of the international field trial. A report from the WHOQOL group. Quality of Life Research, 13, 299-310. https://doi.org/10.1023/ B:QURE.0000018486.91360.00

Steuden, S., \& Janowski, K. (2001). Zastosowanie kwestionariusza Skindex do pomiaru jakości życia u pacjentów z łuszczycą [Application of the Skindex questionnaire to measure quality of life in patients with psoriasis]. Przeglad Dermatologiczny, 88, 41-48.

Szabo, S. on behalf of the WHOQOL Group (1996). The World Health Organization Quality of Life
(WHOQOL) assessment instrument. In B. Spilker (Ed.), Quality of life and pharmacoeconomics in clinical trials (2nd ed., pp. 355-362). Philadelphia, NY: Lippincott-Raven Publishers.

Szepietowski, J., Salomon, J., Finley, A. Y., Klepacki, A., Chodynicka, B., Marionneau, N., Charles, T., \& Myon E. (2004). Dermatology Life Quality Index (DLQI): Polish version. Clinical Dermatology, 6, 63-70.

Uttjek, M., Dufaker, M., Nygren, L., \& Stenberg, B. (2004). Determinants of quality of life in a psoriasis population in Northern Sweden. Acta Dermato-Venereologica, 84, 37-43. https://doi.org/10. 1080/00015550310015833

Zachariae, R., Zachariae, H., Blomqvist, K., Davidsson, S., Molin, L., Mork, C., \& Sigurgeirsson, B. (2004). Self-reported stress reactivity and psoriasis-related stress of Nordic psoriasis sufferers. Journal of the European Academy of Dermatology and Venereology, 18, 27-36. https://doi.org/10.1111/ j.1468-3083.2004.00721.x

Zalewska, A., Miniszewska, J., Chodkiewicz, J., \& Narbutt, J. (2007). Acceptance of chronic illness in psoriasis vulgaris patients. Journal of the European Academy of Dermatology and Venereology, 21, 235-242. https://doi.org/10.1111/j.1468-3083.2006.01912.x
Life satisfaction and quality of life in psoriasis 